\title{
La responsabilidad internacional de los Estados por actos ilícitos, crímenes internacionales y daños transfronterizos*
}

\author{
The International Responsibility of States \\ for Unlawful Acts, International Crimes and \\ Transboundary Damage
}

\section{Najman Alexander Aizenstatd Leistenschneider**}

\begin{abstract}
SUMARIO: I. Introducción: incumplimiento de las obligaciones internacionales. II. La violación de obligaciones internacionales de ius cogens y los daños transfronterizos como factores que generan la responsabilidad. III. Los actos no prohibidos por el derecho internacional y la responsabilidad por riesgo. IV. Las consecuencias de la responsabilidad internacional. V. La futura codificación de la responsabilidad y complementariedad entre responsabilidad del individuo y del Estado.
\end{abstract}

* Artículo recibido el XX de XXXXX de 2011 y aceptado para su publicación el XX de XXXX de 2011.

** Profesor de Derecho en la Universidad Rafael Landivar y Universidad del Istmo; Máster en Derecho por la Universidad de Yale; Abogado Visitante Profesional de la Corte Interamericana de Derechos Humanos (2011), Research Fellow del Instituto Max Planck de Derecho Público Comparado y Derecho Internacional Público en Alemania (2010). Acreditado para el ejercicio Profesional en Guatemala y en el Estado de Nueva York. Email: alexander@aizenstatd. com. El autor desea dedicar este trabajo a la memoria del doctor Francisco Villagrán Kramer, distinguido internacionalista y miembro de la Comisión de Derecho Internacional, con gratitud y admiración. 
RESUMEN: Este trabajo persigue explicar los alcances de la responsabilidad internacional del Estado en relación a su participación en actos prohibidos por el derecho internacional, como crímenes internacionales, y por actos que aunque son legalmente permisibles, causan o pueden llegar a causar daños en el territorio o la población de otros Estados. Se discuten distintos tipos de responsabilidad estatal que aún se encuentran en etapa formativa. Se analizan los avances convencionales y jurisprudenciales. Se explican los supuestos que hacen surgir la responsabilidad internacional y las consecuencias de estos. Se defiende la diferenciación entre ilícitos y crímenes internacionales y se sostiene que las consecuencias entre uno y otro también deben de ser distintas, razón por la cual es fundamental su codificación y desarrollo en el derecho internacional.

Palabras Clave: Responsabilidad del Estado, Daños Transfronterizos, Crímenes Internacionales, Comisión de Derecho Internacional, Ius Cogens, Hecho Internacionalmente Ilícito, Responsabilidad Individual.

ABSTRACT: The article aims to explain the scope of international responsibility of the State in relation to their involvement in acts prohibited by international law as international crimes, and acts that are legally permissible though, cause or could cause damage to the territory or population of other States. We discuss different types of State responsibility that are still in formative stage. It discusses the conventional and jurisprudential developments. It explains the assumptions that give rise to international responsibility and the consequences of these. We defend the distinction between international crimes and illegal acts and argued that the consequences of each other must also be different, why it is essential to its development and codification of international law.

Keywords: State Responsibility, Transboundary Harm, International Crimes, International Law Commission, Jus Cogens, InternationallyWrongful Acts, Individual Responsibility.

RESUME: Ce document a l'intention d'expliquer les portées de la responsabilité internationale en relation avec leur participation dans des actes interdits par le droit international comme des crimes internationaux, et les actes qui bien que sont juridiquement admissibles, causant ou peuvent causer des dommages au territoire ou la population d'autres États. On discute sur les différents types de responsabilité des États qui sont encore en phase de formation. On examine les évolutions conventionnelles et jurisprudentielles. On explique les hypothèses qui donnent lieu à une responsabilité internationale et les conséquences de ces derniers. On défend la distinction entre les illicites et crimes internationaux et on soutient que les conséquences sont également différentes, ca c'est la raison par laquelle est fondamental sa codification et développement dans le droit international.

Mots-clés: Responsabilité de l'État, le dommage transfrontière, les crimes internationaux, la Commission du droit international, jus cogens, fait internationalement illicite, la responsabilité individuelle. 
Al igual que la mayoría de leyes, las normas internacionales son rara vez ejecutadas coercitivamente, pero son usualmente obedecidas

Harold Koh

El cumplimiento voluntario por parte de los Estados de las normas del derecho internacional ha sido un fenómeno complejo y difícil de explicar. En términos generales, las normas internacionales son obedecidas voluntariamente y de manera constante por los actores del derecho internacional. Podría argumentarse que esto obedece a la posibilidad de incurrir en sanciones y a la implementación de mecanismos judiciales, arbitrales y de control cuyo objetivo es garantizar la eficacia de las normas. Sin embargo, la mayoría de mecanismos usualmente no cuentan con procesos coercitivos que impongan al Estado su cumplimiento, ni explican el cumplimiento voluntario en sistemas carentes de entidades adjudicadoras de disputas. En gran parte, el derecho internacional se fundamenta en el cumplimiento voluntario. Algunas escuelas de pensamiento sostienen que el cumplimiento de las normas internacionales se sustenta en la percepción de legitimidad del ordenamiento y obedece a consideraciones elementales de justicia. ${ }^{1}$ Por otro lado, el profesor Henkin sostuvo que el cumplimiento voluntario es el producto de un cálculo utilitarista en donde se sopesan las ventajas del cumplimiento en relación a las desventajas del incumplimiento. ${ }^{2}$ Otros sostienen que esto responde a una estructura organizacional internacional en donde los Estados no desean ser percibidos como extraños a los modelos que se basan en el cumplimiento de obligaciones internacionales. ${ }^{3}$ Más recientemente, las teorías que apoyan al Proceso Legal Transnacional argumentan que el cumplimiento del derecho internacional obedece a una suma de factores interactivos que vinculan a elementos internos y

1 Véase Franck, Thomas M., The Power of Legitimacy Among Nations, 1990.

2 Henkin, Louis, How Nations Behave, 2 ed., 47, 1979.

3 Véase Abram Chayes citado por Hongju Koh, Harold, cit., 2601 (1997). 
externos del Estado en relación a su propia comunidad nacional con la comunidad internacional. ${ }^{4}$ Es posible considerar también una mezcla de estos factores. La escuela de New Haven, representada por los profesores Myres McDougal y W. Michael Reisman, ve al derecho internacional no como un medio, sino como un proceso de decisiones autoritativas cuyo objetivo es contribuir al orden público mundial y la dignidad humana, de ahí que se enfoque no en las normas sino en la toma de decisiones. ${ }^{5}$ No obstante la teoría que se apoye, podemos concluir que en términos generales los Estados usualmente cumplen o aspiran cumplir con sus obligaciones internacionales y que esto es deseable.

El profesor Henkin sostuvo que "casi todas las naciones cumplen casi todos los principios del derecho internacional y casi todas sus obligaciones casi todo el tiempo". ${ }^{6}$ De esto necesariamente resulta que en varias oportunidades existan incumplimientos, lo que conlleva una consecuencia y acarrea la responsabilidad internacional del Estado. Además, en ciertas condiciones confiere al afectado el derecho a una reparación. La responsabilidad estatal frente a un incumplimiento es un principio general del derecho internacional firmemente establecido. ${ }^{7}$ Este principio ha sido reiterado constantemente por la jurisprudencia internacional. Al efecto, y para resaltar este punto, pueden citarse las decisiones de la Corte Permanente Internacional de Justicia en el Caso de los Fosfatos en Marruecos y de la Fábrica en Chorzow. ${ }^{8}$ Asimismo, puede citarse a su sucesora, la Corte Internacional de Justicia, en el Caso del Canal de Corfú, el Caso Relativo a las Actividades Militares y Paramilitares en Nicaragua y Contra Nicaragua y el Caso Relativo al Proyecto Gabcíkovo-Nagymaros, entre

4 Harold Hongju Koh, cit., 2653 (1997).

5 Véase, por ejemplo, Reisman, W. Michael, "In Defense of World Public Order", 95 The American Journal of International Law 833-835, 2001, y Reisman, W. Michael, "The View from the New Haven School of International Law", International Law in Contemporary Perspective, Nueva York, Foundation Press, 1992.

6 Henkin, Louis, How Nations Behave. 2a. ed., 47, 1979.

7 Véase Browlie, Ian, Principles of Public International Law, 5a. ed., Oxford University Press, 1998, p. 436, y Crawford, James, The International Law Commission's Articles on State Responsibility - Introduction, Text and Commentaries, Cambridge University Press, 2002, pp. 77-80.

8 Véase, por ejemplo, Corte Permanente Internacional de Justicia. Caso de los Fosfatos en Marruecos (Objeciones Preliminares), 1938 P.C.I.J., Serie A/B, núm. 74; Caso de la Fábrica en Chorzow (Fondo), 1928, P.C.I.J. Serie A, núm. 17, entre otros. 
muchos otros. ${ }^{9}$ La responsabilidad internacional también es un principio firmemente establecido en materia arbitral desde inicios del siglo $\mathrm{XX} .{ }^{10}$ Incluso tribunales regionales especializados, como la Corte Interamericana de Derechos Humanos, han destacado esta obligación al señalar que "es un principio de Derecho Internacional que toda violación de una obligación internacional que haya producido daño comporta el deber de repararlo adecuadamente". ${ }^{11}$

Para que exista un incumplimiento internacional debe existir una conducta que sea atribuible al Estado y que constituya una violación de una obligación internacional. ${ }^{12}$ A esto cabe señalar que también puede generarse responsabilidad internacional del Estado por hechos cometidos entre particulares, por ejemplo, cuando sus agentes tenían conocimiento de la situación y no tomaron medidas razonables para evitarla o cuando faltaron a su obligación de sancionarla. ${ }^{13}$ La caracterización de legalidad de la actividad atribuible al Estado debe realizarse también conforme al derecho internacional, de ahí que no es posible argumentar

9 Véase, por ejemplo, Corte Internacional de Justicia. Caso del Canal de Corfú (Fondo), I.C.J. Reports 1949; Caso Relativo a las Actividades Militares y Paramilitares en Nicaragua y Contra Nicaragua (Nicaragua contra los Estados Unidos de América), I.C.J. Reports 1986, Caso Relativo al Proyecto Gabĉ́ḱkovo-Nagymaros (Hungría/Eslovaquia) I.C.J. Reports 1997, entre otros.

10 Spanish Zone of Morocco Claims. (Great Britain v. Spain) (1924) 2 United Nations, Reports of International Arbitral Awards (R.I.A.A). 615.

11 Corte Interamericana de Derechos Humanos, Caso Valle Jaramillo y otros vs. Colombia. Fondo, Reparaciones y Costas, sentencia del 27 de noviembre de 2008, serie C, núm. 192 párr. 198, y Caso Velásquez Rodríguez vs. Honduras. Reparaciones y Costas, sentencia del 21 de julio de 1989, serie C, núm. 7 párr. 25.

12 Artículo 2. Artículos de la Comisión de Derecho Internacional sobre la Responsabilidad Internacional del Estado por Hechos Internacionalmente Ilícitos, Asamblea General de las Naciones Unidas Res. A/RES/56/83, 28 de enero de 2002.

13 Véase, por ejemplo, Corte Interamericana de Derechos Humanos, Caso de la Masacre de Pueblo Bello vs. Colombia. Fondo, Reparaciones y Costas, sentencia del 31 de enero de 2006, serie C, núm. 140, párr. 113 y 123; Caso de la Masacre de la Rochela vs. Colombia. Fondo, Reparaciones y Costas, sentencia del 11 de mayo de 2007, serie C, núm. 163, párr. 102; Caso Valle Jaramillo y otros vs. Colombia. Fondo, Reparaciones y Costas, sentencia del 27 de noviembre de 2008, serie C, núm. 192, párr. 77 y 78; Corte Europea de Derechos Humanos, Case of Kiliç v. Turkey, app. núm. 22492/93, Judgment of 28 March 2000. § 6263, y Case of Osman v. The United Kingdom, núm. 87/1997/871/1083, Judgement of 28 October $1998 \S 115$. 
que la conducta era legalmente permisible bajo el ordenamiento nacional para justificar su incumplimiento. ${ }^{14}$ La responsabilidad estatal es además independiente de la responsabilidad individual en que pueden incurrir sus agentes u otras personas cuya conducta pueda ser atribuida al Estado. Si bien históricamente esta distinción no siempre ha estado claramente delimitada, con el surgimiento de los Tribunales Penales Internacionales se ha reiterado la separación e independencia entre responsabilidad estatal e individual. Pero esta diferenciación es aún novedosa en el derecho internacional y puede generar confusión. Hoy en día es un principio reconocido del derecho internacional que los individuos son también penalmente responsables por violaciones al derecho internacional, independientemente la regulación nacional interna. Sin embargo, antes del Tribunal de Núremberg era generalmente aceptado que sólo a los Estados se les podía sancionar por violaciones al orden internacional. ${ }^{15} \mathrm{Al}$ efecto, el Tribunal de Núremberg señaló que "los crímenes contra el derecho internacional son cometidos por hombres, no por entidades abstractas, y sólo castigando a los individuos que cometan esos crímenes pueden las provisiones del derecho internacional hacerse valer". ${ }^{16}$ Así se ha venido desarrollando un régimen de responsabilidad estatal e individual conjunta.

Este trabajo persigue hacer notar que la responsabilidad individual y del Estado coexisten y no son mutuamente excluyentes. ${ }^{17}$ En estos casos la responsabilidad estatal no exime al individuo de su responsabilidad individual y tampoco la responsabilidad individual debe eximir al Estado de su propia responsabilidad internacional. El nuevo enfoque en la responsabilidad del individuo es un avance bienvenido producto del establecimiento de los tribunales ad hoc y de una nueva orientación sobre

14 Artículo 27 de la Convención de Viena sobre el Derecho de los Tratados de 1969.

15 Jørgensen, Nina H., The Responsibility of States for International Crimes, Oxford Monographs in International Law, Oxford U. Press, 2003, p. 139.

16 Tribunal Militar Internacional de Núremberg, The Trial of the Major War Criminals. Proceedings of the International Militar Tribunal sitting at Nuremberg, Germany, vol. 22, p. 447 (London, HMSO 1950).

17 Sobre este tema véase Cançado Trindade, Augusto Antônio, Complementarity between State Responsibility and Individual Responsibility for Grave Violations of Human Rights: The Crime of State Revisited en Maurizio Ragazzi (ed.) International Responsibility Today, Konigklijke Brill NV, The Netherlands, 2005, p. 258. 
el papel de los individuos en el derecho internacional. Sin embargo, esto no debe de desviar el enfoque de la comunidad internacional hacia el desarrollo progresivo y codificación de la responsabilidad estatal cuyos avances más representativos provienen de la Comisión de Derecho Internacional. Para ello, este trabajo analizará los tipos de responsabilidad en los que puede incurrir el Estado, enfocándose en la responsabilidad internacional por actividades relacionadas con ilícitos internacionales, los crímenes internacionales, y, la responsabilidad por actos lícitos que causen o puedan causar daños transfronterizos. En cada uno de estos temas se hará referencia a sus conceptos y efectos más importantes, y a su vez, a los aspectos que aún presentan dificultades en el ámbito internacional. Finalmente, se defenderá la armonía y complementación entre la responsabilidad estatal e individual en aras de garantizar el cumplimiento de las obligaciones internacionales.

\section{LA VIOLACIÓN DE OBLIGACIONES INTERNACIONALES DE IUS COGENS Y LOS DAÑOS TRANSFRONTERIZOS COMO FACTORES QUE GENERAN LA RESPONSABILIDAD}

Para explicar la responsabilidad estatal bajo el derecho internacional es necesario primero hacer referencia a los tipos de responsabilidad en los que puede incurrir el Estado. Además es importante diferenciar aquellas áreas en las que resulta imperativo que se retomen los esfuerzos de codificación. El derecho internacional contemporáneo permite distinguir entre la responsabilidad internacional generada por hechos ilícitos atribuibles a los Estados y la responsabilidad que, sin que exista un hecho ilícito, surge de la realización de actividades que no están prohibidas cuando producen daños a terceros. ${ }^{18}$ De ahí que, de conformidad con el derecho internacional, los Estados puedan incurrir en responsabilidad internacional también cuando sus actos lícitos producen daños transfronterizos a otros Estados o a sus habitantes.

18 La responsabilidad internacional puede surgir a partir de la contravención a una norma establecida en un instrumento internacional o a una obligación internacional aunque no provenga de un tratado. El término ilícito no debe confundirse con el concepto de delito en el ordenamiento jurídico nacional. 
Asimismo, el derecho internacional permite distinguir entre la responsabilidad de los Estados por hechos u omisiones que constituyen hechos ilícitos y la responsabilidad por hechos ilícitos excepcionalmente graves que contravengan normas imperativas de derecho internacional, conocidas como ius cogens. ${ }^{19}$ Las obligaciones de esta naturaleza no admiten reserva o pacto en contrario, surgen independientemente de los tratados internacionales y son debidas a la comunidad internacional en su conjunto. ${ }^{20}$ Son pocas las normas que han alcanzado este carácter, pues se consideran de la más alta jerarquía por sobre cualquier otra norma y principios. Si bien el concepto de ius cogens es notablemente más amplio que el de crímenes internacionales, se puede decir que los siguientes crímenes internacionales han alcanzado el nivel de ius cogens: genocidio, tortura, crímenes contra la humanidad, piratería, esclavitud, discriminación racial, apartheid y agresión, entre otros. ${ }^{21}$ Se ha señalado que estos crímenes "afectan los intereses de la comunidad de naciones en su conjunto porque amenazan la paz y seguridad de la humanidad...”. ${ }^{22}$ La responsabilidad internacional de los Estados incluso puede derivarse de un crimen internacional sin que exista propiamente responsabilidad penal de los Estados. ${ }^{23}$ Claro está que aunque teoréticamente algunos han defendido, como el Tribunal Penal Internacional para la Ex Yugo-

19 El concepto de ius cogens se encuentra definido en el artículo 53 de la Convención de Viena sobre el Derecho de los Tratados. Sobre ius cogens y crímenes internacionales véase: Nina H. Jørgensen, op. cit., pp. 85-92.

20 Véase Corte Internacional de Justicia. Caso Relativo a la Barcelona Traction, Light and Power Company (Segunda Phase) I.C.J. Reports 1970.

21 Véase, entre otros, Cassese, Antonio, International Law, Oxford U. Press, 2005, pp. 445 y 446; Antonio Cançado Trindade, Jus Cogens: The Determination and the Gradual Expansion of Its Material Content, en XXXV Curso de Derecho Internacional Organizado por el Comité Jurídico Interamericano - OAS (2008); Cherif Bassiouni, M., "International Crimes, Ius Cogens and Obligations Erga Omnes”, Law and Contemporary Problems 68, 54 núm. 4 1997; Comisión Internacional de Juristas. Impunidad y Graves Violaciones de Derechos Humanos, Guía para Profesionales núm. 3, Ginebra, 2008, p. 20; Pastor Ridruejo, José A., Curso de Derecho Internacional Público y Organizaciones Internacionales, Tecnos, 2009, p. 543, y Najman Alexander Aizenstatd Leistenschneider, "Origen y evolución del concepto de genocidio", 25 Revista de la Facultad de Derecho de la U. Francisco Marroquín, 11, 2007.

22 Cherif Bassiouni, M., "International Crimes, Ius Cogens and Obligations Erga Omnes". Law and Contemporary Problems 69, 54 núm. 4, 1997.

23 Sobre los crímenes internacionales véase Cherif Bassiouni, op. cit., pp. 64-74. 
slavia, que es posible que un solo individuo pueda cometer un crimen internacional, generalmente es necesaria la participación de una colectividad, como un Estado para cometer delitos como el genocidio y otros crímenes internacionales. ${ }^{24}$ Un Estado puede ser responsable de la comisión de un crimen internacional. Esto debido a que existe responsabilidad que puede surgir a partir de la acción, omisión, consentimiento o aquiescencia de agentes del Estado en esos hechos. La Convención para la Prevención y la Sanción del Delito de Genocidio y la Convención contra la Tortura y Otros Tratos o Penas Crueles, Inhumanos o Degradantes sirven para ilustrar este punto. ${ }^{25}$ Así también las decisiones de la Corte Internacional de Justicia en los casos concernientes a la Aplicación de la Convención sobre la Prevención y Sanción del Delito de Genocidio y los casos sobre la Legalidad del Uso de la Fuerza interpuestos por Yugoslavia en contra de los Estados Unidos de América, Canadá y varios países europeos. ${ }^{26}$ Sin embargo, tratándose de Estados que no hubieren ratificado un instrumento internacional que penalice los delitos contra

24 Tribunal Penal Internacional para la Ex Yugoslavia. Fiscal v. Jelisic, IT-95-10-T, [14 Diciembre 1999], párr. 100 y 101.

25 La Convención para la Prevención y la Sanción del Delito de Genocidio (1949) y la Convención contra la Tortura y Otros Tratos o Penas Crueles, Inhumanos o Degradantes (1984).

26 Corte Internacional de Justicia. Caso Concerniente a la Aplicación de la Convención sobre la Prevención y Sanción del Delito de Genocidio (Croacia v. Serbia), Objeciones Preliminares. I.C.J. Reports 2008; Caso Concerniente a la Aplicación de la Convención sobre la Prevención y Sanción del Delito de Genocidio (Bosnia y Herzegovina v. Yugoslavia) - Objeciones Preliminares. I.C.J. Reports 1996; Legalidad del Uso de la Fuerza (Yugoslavia v. España), Medidas Provisionales, I.C.J. Reports 1999; Legalidad del Uso de la Fuerza (Yugoslavia v. Canada), Medidas Provisionales, I.C.J. Reports 1999; Legalidad del Uso de la Fuerza (Yugoslavia v. Estados Unidos de América), Medidas Provisionales, I.C.J. Reports 1999; Legalidad del Uso de la Fuerza (Yugoslavia v. Reino Unido) Medidas Provisionales, I.C.J. Reports 1999; Legalidad del Uso de la Fuerza (Yugoslavia v. Portugal), Medidas Provisionales, I.C.J. Reports 1999; Legalidad del Uso de la Fuerza (Yugoslavia v. Países Bajos), Medidas Provisionales, I.C.J. Reports 1999; Legalidad del Uso de la Fuerza (Yugoslavia v. Italia), Medidas Provisionales, I.C.J. Reports 1999; Legalidad del Uso de la Fuerza (Yugoslavia v. Alemania), Medidas Provisionales, I.C.J. Reports 1999; Legalidad del Uso de la Fuerza (Yugoslavia v. Francia), Medidas Provisionales, I.C.J. Reports 1999 y Legalidad del Uso de la Fuerza (Yugoslavia v. Bélgica), Medidas Provisionales, I.C.J. Reports 1999. 
el ius cogens, su responsabilidad subsiste de manera independiente, de conformidad con el derecho internacional general. ${ }^{27}$

Lo expuesto permite esclarecer que tratándose de los llamados delitos se está frente a la responsabilidad internacional objetiva de los Estados. En el caso de hechos ilícitos excepcionalmente graves atribuibles o imputables a los Estados, la responsabilidad internacional del Estado es también agravada, y puede manifestarse con sanciones ejemplificativas o disuasivas..$^{28}$ Además, la responsabilidad en estos casos puede conllevar la obligación de realizar cambios legislativos internos o incluso modificar su norma fundamental. ${ }^{29}$ También incluye obligaciones de terceros Estados, como el no reconocimiento de la conducta ilícita y la obligación de no cooperar. Pero debe aclararse que en relación a su participación en la comisión de crímenes internacionales no se criminaliza propiamente al Estado, es decir, no se le atribuye responsabilidad penal, sino responsabilidad internacional y en consecuencia la obligación de hacer reparaciones y otorgar garantías de no repetición.

Los crímenes internacionales son hechos excepcionalmente graves para la comunidad internacional de Estados en su conjunto y constituyen delicta iuris gentium. Por tal motivo la responsabilidad del Estado surge por su participación en un hecho ilícito internacional, pero la responsabilidad no está limitada a hechos ilícitos, también se incurre en responsabilidad cuando no exista un hecho ilícito propiamente, si se realizan actividades sine delicto que causen o puedan causar daños transfronterizos a otros Estados. La Corte Internacional de Justicia ya advirtió en su Opinión Consultiva sobre Legalidad de la Amenaza o Uso de Armas Nucleares que la: "obligación general de los Estados de asegurar que las actividades dentro de su jurisdicción y control respeten el medio ambiente de otros Estados o de áreas más allá de su control nacional es ahora parte del corpus del derecho internacional en relación al medio

27 Villagrán Kramer, Francisco, El largo brazo de la justicia penal internacional, Guatemala, Corte Suprema de Justicia, Unidad de Modernización de la Justicia, 2001.

28 Cançado Trindade, Complementarity..., cit., p. 266.

29 Nolkaemper, André, "State Responsibility for International Crimes. In Diversity in International Law”, en Constantinidis, Aristotle (ed.), Essays in Honour of Professor Kalliopi Koufa, Martinus Nijhoff Publishers, 2009, p. 29. 
ambiente".$^{30}$ Además en el Caso del Canal de Corfú había indicado que "es la obligación de todo Estado no permitir conscientemente que su territorio sea usado para actos contrarios a los derechos de otros Estados". ${ }^{31}$ En relación a los daños transfronterizos, la responsabilidad del Estado es también un factor determinante, aun cuando las actividades realizadas también hagan responsable directamente al individuo o entidad que los causa.

Situados en este terreno recordaremos que en el ámbito internacional, al igual que en el civil, el uso de mecanismos, instrumentos, aparatos, o sustancias peligrosas por sí mismos, por la velocidad que desarrollan, por su naturaleza explosiva o inflamable, por la energía que conduzcan o, por otras causas análogas, obliga a quienes los usan no sólo a actuar con la debida diligencia sino también a responder por los daños y perjuicios que causen. Salvo, desde luego, por dolo o participación de la víctima. En consecuencia, progresivamente se ha venido imponiendo en la esfera internacional la teoría del riesgo; sobre todo, tratándose de actividades o sustancias peligrosas. A medida que se extienden y generalizan los avances tecnológicos y, con ello, los riesgos de causar daños transfronterizos, la distinción entre responsabilidad objetiva y responsabilidad por riesgo gana terreno y espacio propio en el ámbito internacional. La tragedia que causó el derrame de hidrocarburos por el tanquero Prestige en las costas de España, Portugal y de Francia a fines de 2002, y más recientemente el derrame petrolero de la plataforma petrolera Deepwater Horizon, operada por la corporación británica BP en el Golfo de México, ilustran la magnitud y diversidad de preocupaciones ambientales y jurídicas que ello puede generar. $^{32}$

Lo peligroso y lo ultra peligroso se vienen reconociendo como factores no de simple riesgo sino de alto riesgo, llevando a los Estados a establecer regímenes especiales vía tratados a fin de que dichos actos

30 Corte Internacional de Justicia, Legalidad de la amenaza o uso de armas nucleares, Opinión Consultiva, I.C.J., Reports 1996, párr. 29.

31 Corte Internacional de Justicia, Caso del Canal de Corfú (Fondo), I.C.J., Reports 1949 , p. 22.

32 Gómez, Luis y Ordaz, Pablo, "SOS: peligro no definido, crónica: catástrofe ecológica en Galicia la crónica negra del 'Prestige'”, El País, 1o. de diciembre de 2002, y BBC, "US Oil Spill Threatens 'way of life', governor warns", 2 de mayo de 2010, en: http://news.bbc. co.uk/2/hi/americas/8656627.stm (27 de mayo de 2011). 
queden sujetos a medidas de prevención destinadas a evitar riesgos de causar daños transfronterizos y a la obligación de reparar los daños causados, por ejemplo, el Convenio Internacional sobre Responsabilidad Civil por Daños debidos a la Contaminación de las Aguas del Mar por Hidrocarburos y la Convención Internacional de Protección Fitosanitaria. ${ }^{33}$ Además, como lo ha señalado la Corte Internacional de Justicia en el Caso Concerniente a las Fábricas de Pulpa en el Rio Uruguay, puede existir también una obligación de los Estados de notificar a los Estados vecinos con el objetivo de reducir el impacto que resulta de actividades riesgosas. ${ }^{34}$

De manera paralela a la internacionalización de la responsabilidad por riesgo existen los conflictos de leyes y de jurisdicción, dado que en tanto no esté vigente un tratado que establezca la responsabilidad por riesgo en forma general corresponde a las jurisdicciones nacionales resolver lo relativo a los daños. Por ahora persisten muchas interrogantes. Como se sabe, algunos países siguen en materia de daños la regla del lugar donde se cometió el acto, otros la regla del lugar en el que se produce el daño. A uno y otro régimen se añade la regla del domicilio común. En cuanto a la jurisdicción también se pueden registrar conflictos entre el país en cuyo territorio se genera el daño, aquel en donde se realizó el acto, las aguas internacionales, entre otros supuestos. De ahí que varias de las normas que rigen la responsabilidad estatal en estos casos aún se encuentren en etapa formativa.

\section{LOS ACTOS NO PROHIBIDOS POR EL DERECHO INTERNACIONAL Y LA RESPONSABILIDAD POR RIESGO}

A lo largo de muchos años se debatió si era el daño causado o la violación de obligaciones internacionales lo que generaba la responsabilidad

33 Convenio Internacional sobre Responsabilidad Civil por Daños Debidos a la Contaminación de las Aguas del Mar por Hidrocarburos. Bruselas (1969), y Convención Internacional de Protección Fitosanitaria. Roma (1997).

34 Corte Internacional de Justicia, Caso Concerniente a las Fábricas de Pulpa en el Rio Uruguay (Argentina v. Uruguay), I.C.J., Reports, p. 115. 
internacional. El tema fue finalmente esclarecido por la Comisión de Derecho Internacional al precisar que es la violación o el incumplimiento de una obligación internacional lo que en derecho internacional genera la responsabilidad. ${ }^{35}$ Es decir que el hecho generador de la responsabilidad internacional por hechos ilícitos no es el daño, sino la violación o el incumplimiento de una obligación internacional, sea ésta convencional o consuetudinaria. El incumplimiento de la obligación internacional implica por sí mismo un perjuicio y por lo tanto no es necesario que en adición a éste existan daños económicos. Por ende, el infractor debe, en primer lugar, cesar el acto violatorio y proporcionarle al Estado lesionado garantía de no repetición. La garantía de no repetición ya ha sido reconocida también como parte de la costumbre internacional por la Corte Internacional de Justicia en el Caso LaGrand y el Caso Avena y otros Nacionales Mexicanos. ${ }^{36}$ De no ser posible la restitución, el Estado debe reparar los daños causados, si los hubiere, y otorgar reparaciones como forma de compensación o satisfacción, o ambas. ${ }^{37} \mathrm{Tal}$ es, en apretada síntesis, el régimen de las consecuencias de la responsabilidad internacional.

En cambio, tratándose de actos no prohibidos por el derecho internacional, la responsabilidad es sine delicto y el daño causado es elemento de la responsabilidad de los Estados. Desde luego, no se trata de daños menores sino de daños de naturaleza o con alcances transfronterizos que se originan en un Estado o en jurisdicción internacional y se producen en el territorio de otro Estado o en lugares bajo la jurisdicción o control del Estado que sufre el daño. No es necesario que los Estados interesados tengan fronteras comunes, ya que se pueden originar en alta mar

35 Artículos 1 y 2. Artículos de la Comisión de Derecho Internacional sobre la Responsabilidad Internacional del Estado por Hechos Internacionalmente Ilícitos, Asamblea General de las Naciones Unidas Res. A/RES/56/83, 28 de enero de 2002.

36 Corte Internacional de Justicia, Caso LaGrand (Alemania contra los Estaddos Unidos de América), Fondo, I.C.J., Reports, 2001, p. 513, y Caso Avena y otros Nacionales Mexicanos, Fondo, I.C.J., Reports, 2004, p. 69. Véase también André Nolkaemper, "State Responsibility...”, cit., pp. 27-29.

37 Corte Internacional de Justicia, Caso Concerniente al Proyecto Gabčíkovo-Nagymaros (Hungría/Eslovaquia), I.C.J., Reports 1997, párr. 152; Consecuencias Legales de la Construcción de un Muro en el Territorio Ocupado de la Autoridad Palestina, Opinión Consultiva, I.C.J. Reports 2004 (I), párr. 152 y 153; Aplicación de la Convención sobre la Prevención y Sanción del Delito de Genocidio (Bosnia y Herzegovina v. Serbia y Montenegro), I.C.J. Reports 2007, párr. 460. 
o en el espacio exterior. Desde luego, siempre existe diferencia entre daños transfronterizos simples y daños transfronterizos de magnitud, incluyendo los llamados "catastróficos" como suelen ser los daños por el derrame de hidrocarburos o accidentes en centrales nucleares.

En cuanto a las violaciones graves de obligaciones internacionales atribuibles al Estado, como la agresión internacional, prohibida por la Carta de las Naciones Unidas y recientemente incluida como una violación bajo la competencia de la Corte Penal Internacional, la regla que la prohíbe obliga a la reparación. ${ }^{38}$ El dolo también es un elemento importante que agrava la responsabilidad estatal, dando lugar a otra clase de consecuencias, como las que puede imponer el Consejo de Seguridad de las Naciones Unidas en casos de amenazas a la paz, quebrantamiento de la paz y actos de agresión. ${ }^{39}$

Tratándose de actividades peligrosas y ultra peligrosas no prohibidas por el derecho internacional, la distinción entre responsabilidad objetiva por daño o por riesgo cobra relevancia. Hasta ahora la regla prevaleciente conforme al derecho internacional general ha sido la responsabilidad que generan los hechos ilícitos. En cambio, tratándose de los actos y de las actividades peligrosas y ultra peligrosas permitidas, el factor determinante de la responsabilidad es el riesgo. De ahí que la responsabilidad sine delicto sea, por ahora, la excepción. Esto significa que hasta que esta clase de responsabilidad no alcance la categoría de regla general de derecho internacional general tendría que establecerse por vías convencionales. ${ }^{40}$ Por lo cual, para garantizar certeza, es necesario el desarrollo internacional de este tipo de responsabilidad a nivel general. Existen, claro, circunstancias en las cuales el riesgo inminente

38 Artículos 1o. y 39 de la Carta de Naciones Unidas y Declaración sobre los Principios de Derecho Internacional referente a las relaciones de amistad y a la cooperación entre los Estados de conformidad con la Carta de las Naciones Unidas. Asamblea General Res. No. A/8082 (1970). Sobre la agresión en el Estatuto de la Corte Penal Internacional véase artículo 8 bis del Estatuto de Roma de la Corte Penal Internacional (1998), según resolución de los Estados parte de 2010 (debe aclararse que en ese caso se refiere a responsabilidad penal individual).

39 Artículo 39 de la Carta de las Naciones Unidas. Véase, también, Cot Jean, Pierre y Pellet, Allain, La Charte des Nations Unies, París, Económica, 1991, y Vallarta Marrón, José Luis, "La incorporación del crimen de agresión en el Estatuto de la Corte Penal Internacional", Anuario Mexicano de Derecho Internacional, vol. XI, 2011, pp. 435-461.

40 Véase Cot y Pellet, op. cit. 
puede ser objeto de medidas provisionales ante la Corte Internacional de Justicia, como por ejemplo las medidas solicitadas por Costa Rica en contra de Nicaragua en relación a ciertas actividades en el río San Juan. ${ }^{41}$

Para el desarrollo de este tipo de responsabilidad a nivel general, y no como caso de primera impresión, conviene tener presentes los criterios que entran en juego en relación a los riesgos de causar daños transfronterizos. En especial, puede considerarse lo dispuesto en los sistemas legales internos cuando se trata de sustancias tóxicas y actividades peligrosas y ultra peligrosas. No sólo los procesos de producción y conversión sino también la operación, el manejo, el transporte y el trasiego de materiales y de sustancias, tóxicas, peligrosas y ultra peligrosas pueden entrar en terrenos de la responsabilidad internacional sine delicto.

En consecuencia, el transporte y trasiego de hidrocarburos y de materiales radioactivos, de sustancias volátiles, incluyendo los riesgos de vertimientos accidentales en ríos y vías navegables, en el mar o en áreas sujetas a la jurisdicción interna tanto del Estado que realiza la actividad como de terceros, podrían estar sujetos a la responsabilidad por riesgo. De esta suerte, el espectro internacional de la responsabilidad se extiende, y con ello se fortalece el proceso de adopción de medidas tanto en el interior de los Estados como en agrupamientos y comunidades de Estados.

En virtud de que no se trata únicamente de actividades que llevan a cabo los Estados sino también los sectores privados, que hoy en día pueden ejercer papeles más importantes, en algunos campos en los que existen elevados riesgos se pueden compartir las consecuencias de la responsabilidad entre los particulares y los sujetos de derecho internacional que las autorizaron o consintieron.

Al efecto, se ha vuelto práctica corriente acordar límites a la responsabilidad financiera, ya sea entre el Estado y las empresas particulares o bien entre las propias entidades que intervienen en esas actividades y procesos, en otros casos, a contratar obligatoriamente seguros comerciales. El Estado y los operadores de las actividades peligrosas o ultra peligrosas tienden, entonces, a precisar los términos de su relación,

${ }^{41}$ Corte Internacional de Justicia, Medidas Provisionales, relacionadas con Ciertas Actividades Realizadas por Nicaragua en el Área Fronteriza, Orden del 8 de marzo de 2011. 
existiendo en estos casos una tendencia hacia la contratación de seguros. El sistema de la libre empresa y la libertad de transferir los riesgos de una actividad de manera contractual genera un ambiente diferente al que antes existía cuando se abrió paso a la teoría del riesgo. ${ }^{42}$

Es importante hacer notar que los hechos que generan la responsabilidad internacional de los Estados y la responsabilidad de los particulares dan lugar a polémicas entre los Estados y, de la misma manera, a la retorsión y represalias (o contramedidas) cuando existe negativa a resolver esa clase de disputas. Las dos grandes vías que existen - la de las acciones de daños y perjuicios que pueden plantearse ante los tribunales nacionales, y los medios jurídicos de solución de controversias en el plano internacional incluyendo el arbitraje y los tribunales internacionales - constituyen, pues, nuevas áreas para jueces y abogados.

Por último, también conviene tener presentes los mecanismos destinados a evitar las disputas o controversias entre los Estados, y los nuevos mecanismos de solución de controversias que se han establecido en algunos sistemas, principalmente, en el ámbito del derecho internacional del medio ambiente. En especial cabe resaltar la Convención de Basilea sobre el Control de los Movimientos Transfronterizos de los Desechos Peligrosos y su Eliminación, Basilea (1989); el Convenio sobre la Diversidad Biológica, Rio de Janeiro (1992); la Convención de las Naciones Unidas de Lucha contra la Desertificación en los Países afectados por Sequía grave o desertificación, en particular África, París (1994); la Convención sobre el Comercio Internacional de Especies Amenazadas de Fauna y Flora Silvestres (“CITES”) (1979); la Convención sobre los Humedales de Alta Importancia Internacional Especialmente como Hábitat de Aves Acuáticas (“Convención de Ramsar”) (1971), y el Convenio de Estocolmo sobre Contaminantes Orgánicos Persistentes (2001). Además, el Protocolo de Montreal relativo a las Sustancias que Agotan la Capa de Ozono y el Protocolo de Kyoto de la Convención Marco de las Naciones Unidas sobre el Cambio Climático ponen acento en mecanismos no conformacionales de cooperación. ${ }^{43}$ Es importante que estos

\footnotetext{
42 Véase Villagrán Kramer, Francisco, El derecho internacional ambiental más allá del "Soft Law", Organización de los Estados Americanos. Jornadas de Derecho Internacional, 2000.

43 Protocolo de Montreal Relativo a las Sustancias que Agotan la Capa de Ozono (1987) y sus enmiendas y Protocolo de Kyoto de la Convención Marco de las Naciones Unidas sobre el
} 
avances en la codificación y desarrollo progresivo del derecho internacional sean consecuentes y armoniosos con las teorías que sustentan la responsabilidad estatal e individual en otros campos, como los crímenes internacionales. De ahí que no se desvíe el enfoque necesariamente en sólo uno de los actores.

\section{LAS CONSECUENCIAS \\ DE LA RESPONSABILIDAD INTERNACIONAL}

Incursionaremos, por último, en las consecuencias internacionales que generan los actos no prohibidos por el derecho internacional que pueden ocasionar daños transfronterizos, así como las que se derivan de los crímenes internacionales.

Por mucho tiempo se debatió si el régimen legal de las consecuencias de los hechos ilícitos se hacía extensivo a las consecuencias de los actos no prohibidos por el derecho internacional. Además se debatió si las consecuencias internacionales de los crímenes internacionales serían para los Estados las mismas que las de los delitos. Esta postura se sostenía en el argumento de que el régimen legal de la responsabilidad internacional de los Estados tradicionalmente se había considerado unitario, por lo que las consecuencias de esos hechos debían ser en todos los casos las mismas. Unidad versus Pluralidad de regímenes fueron, pues, las variantes que en doctrina y en la Comisión de Derecho Internacional se debatieron, y en cierta medida aún se debaten en el Derecho Internacional. ${ }^{44}$

Además de establecer los tipos de responsabilidad, este trabajo persigue demostrar que los efectos de cada una deben de ser distintos. Por

Cambio Climático (1997). Véase además, generalmente, Loibl, Gerhard, Curso de derecho internacional, Organización de los Estados Americanos, Comité Jurídico Interamericano XXIV, 1997, y Brunee, Jutta y Toope, Stephen J., "Environmental Security and Freshwater Ecosystems Regime Building”, American Journal of International Law 91, núm. 3, 1997.

${ }^{44}$ Véase por ejemplo: Comisión de Derecho Internacional. Fragmentación del Derecho Internacional: Dificultades derivadas de la diversificación y expansión del Derecho Internacional. Informe del Grupo de Estudio de la Comisión de Derecho Internacional Elaborado por Martti Koskenniemi. Doc. No. A/CN.4/L.682. 13 de abril de 2006. 
ejemplo, la distinción entre delitos y crímenes internacionales y de los efectos de su contravención es aún problemática. De ahí que la necesidad de su identificación y posterior estudio se haga necesaria. El proyecto de artículos sobre responsabilidad del Estado de la Comisión de Derecho Internacional representa el intento de codificación sobre la materia más avanzado en derecho internacional, y es el resultado de más de 40 años de trabajo de la Comisión. En el proyecto de artículo 19 en materia de responsabilidad internacional de los Estados de 1996, la Comisión de Derecho Internacional reconoció la existencia de dos categorías de hechos ilícitos: la de los delitos y la de los crímenes internacionales, distinción que llevó a anticipar que las consecuencias internacionales entre uno y otro tendrían que ser, irremisiblemente, distintas. Esa postura que diferenciaba los delitos de los crímenes internacionales ya era conocida desde 1976, cuando fue propuesta por el Relator Especial Roberto Ago. ${ }^{45} \mathrm{La}$ discusión generada llevó a depurar los conceptos y a establecer que, si bien la responsabilidad internacional de los Estados es una y no se divide en penal y civil y tampoco en contractual o extra contractual, las consecuencias legales de los ilícitos y de los crímenes internacionales no pueden ser las mismas. La circunstancia de que los hechos generadores sean distintos, per se, llevaba a sostener que las consecuencias internacionales deberían ser distintas. A esto se agregaba que en el caso de los de los crímenes internacionales en los que los Estados podían tener responsabilidad debían aplicarse medidas o sanciones diferentes. El área de las sanciones abrió, pues, un capítulo aparte, difícil de manejar y deslindar. Sobre todo cuando la limitante era no criminalizar al Estado. Sin embargo, la controversia continuó y el texto de este artículo 19 se eliminó del proyecto en su versión final de 2001, sustituyéndose por el reconocimiento de responsabilidad por el incumplimiento de normas imperativas de derecho internacional en los artículos 40 y $41 .{ }^{46}$ De ahí que hasta el momento el tema aún no se ha resuelto.

45 Fifth report on State responsibility by Mr. Roberto Ago, Special Rapporteur - the internationally wrongful act of the State, source of international responsibility. Doc.A/CN.4/291 and Add. 1 \& 2 and Corr. 1 y Yearbook of the International Law Commission (1976, II, Part 2) $95-112$.

46 Draft Articles on the Responsibility of States for Internationally Wrongful Acts, UN GAR, UN Doc A/56/10 (2001). Para un análisis sobre el resultado de esta sustitución vé- 
Los esfuerzos codificadores de la responsabilidad internacional deben de considerar que el incumplimiento de una obligación internacional necesariamente conlleva la responsabilidad del Estado, independientemente de la naturaleza de la obligación incumplida. ${ }^{47}$ Pero esto no significa que las consecuencias sean idénticas. La responsabilidad de los Estados, se trate de hechos ilícitos simples, de daños transfronterizos causados por actividades no prohibidas por el derecho internacional o por crímenes internacionales, no deben de ser las mismas.

\author{
V. LA FUTURA CODIFICACIÓN DE LA RESPONSABILIDAD \\ Y COMPLEMENTARIEDAD ENTRE RESPONSABILIDAD DEL INDIVIDUO \\ Y DEL ESTADO
}

Históricamente los ensayos de codificación del derecho internacional en el campo de la responsabilidad internacional de los Estados representaron importantes avances, pero no se materializaron en un proyecto que comandare aceptación por medio de la suscripción de un instrumento internacional vinculante por la mayoría de los Estados. Tal fue el caso del proyecto de codificación que se hizo en 1930 por la Sociedad de Naciones $^{48}$. Luego de éste, el más destacado es el esfuerzo que la Comisión de Derecho Internacional ha realizado a partir de 1956 por mandato de la Asamblea General de las Naciones Unidas, sobre todo considerando lo sensible y controversial de la materia y la abundante jurisprudencia internacional y nacional en el tema. Si bien éste no tiene

ase: Wyler, Eric, "From 'State Crime' to Responsibility for 'Serious Breaches of Obligations under Preemptory Norms of General International Law'”, European Journal of International Law, vol. 13, núm. 5, pp. 1147-1160; Gaja, Giorgio, "Should all References to International Crimes Disappear from the ILC Draft Articles on State Responsibility?", European Journal of International Law, vol. 10, núm. 2, 1999, pp. 365-370, y Pellet, Alain, "Can a State Commit a Crime? Definitively, Yes!”, European Journal of International Law, vol. 10, núm. 2, pp. 425-434 (1999).

47 Corte Internacional de Justicia, Caso Relativo al Proyecto Gabĉ́kovo-Nagymaros (Hungría/Eslovaquia) I.C.J., Reports 1997, p. 35.

48 League of Nations, Bases of Discussion for the Conference drawn up by the Preparatory Committee, vol. III: Responsibility of States for Damage caused in their Territory to the Person or Property of Foreigners (LN doc. C.75.M.69.1929V). 
fuerza vinculante convencional, es una referencia obligatoria en materia de responsabilidad internacional.

La tarea iniciada por la Comisión de Derecho Internacional en la década de los años cincuenta concluyó hasta el 2001. Cinco Relatores Especiales le consagraron tiempo a la labor codificadora. ${ }^{49}$ Siguiendo el método de dos lectores, la primera lectura del proyecto de artículos concluyó en 1996, teniendo los gobiernos oportunidad para analizar las propuestas de codificación y la Corte Internacional de Justicia para verificar el efecto codificador de varios de los artículos que figuraban en el texto desde la primera lectura. La segunda lectura inició en 1997 y concluyó en 2001 bajo la supervisión del quinto y último Relator Especial, el profesor James Crawford. El proyecto final y los valiosos Comentarios de la Comisión de Derecho Internacional fueron aprobados por la Asamblea General de las Naciones Unidas en enero de 2002. ${ }^{50} \mathrm{~A}$ pesar de esta labor monumental, aún persisten aspectos de la responsabilidad estatal controvertidos.

En cuanto a la regulación internacional de la responsabilidad por actos no prohibidos por el Derecho Internacional, la Comisión de Derecho Internacional le consagró sus mejores esfuerzos. A criterio de algunos de sus miembros, el tema aún no estaba listo para codificación, por lo que la labor más bien sería en el terreno del desarrollo progresivo del derecho internacional. Sin embargo, los avances en su estudio pusieron de manifiesto que en algunos subtemas, como el de la prevención y la diligencia debida, no sólo existía sólida jurisprudencia y doctrina, sino que los Estados estaban familiarizados con su desarrollo y sus alcances. Asimismo, algunos precedentes, entre los que pueden citarse el Arbitraje del Trail Smelter entre Canadá y los Estados Unidos de América, el Caso del Canal de Corfú entre el Reino Unido y Albania, y el Arbitraje del Lago Lanoux entre Francia y España ofrecían base suficiente para intentar codificar la normativa básica de la responsabilidad por actos no prohibidos por el derecho internacional así como por daños transfronteri-

49 F. V. García Amaddor (1955-1961), Roberto Ago (1963-1979), Willem Riphagen (19791986), Gaetano Arangio-Ruiz (1987-1996) y James Crawford (1997-2001).

50 Comisión de Derecho Internacional sobre la Responsabilidad Internacional del Estado por Hechos Internacionalmente Ilícitos, Asamblea General de las Naciones Unidas Res. A/ RES/56/83, 28 de enero de 2002. 
zos. ${ }^{51}$ Aunque haya concluido la labor de la Comisión sobre este tema, es importante que no se abandonen los esfuerzos que persiguen el desarrollo progresivo y ordenado de este complejo tema que como se expuso en este trabajo aún presenta algunas dificultades.

Por otro lado, el actual enfoque en la responsabilidad de los individuos no debe de disminuir los avances incipientes respecto a la responsabilidad estatal, en particular respecto a los crímenes internacionales. La creación de la Corte Penal Internacional y varios casos de alto impacto ante los Tribunales Penales $A d$ Hoc han reiterado el énfasis en la responsabilidad de los individuos ante violaciones del derecho internacional. Adecuadamente, Sir Hersch Lauterpacht señaló que "al menos que se impute y establezca responsabilidad a personas de carne y hueso, la responsabilidad será de nadie". ${ }^{52} \mathrm{Si}$ bien la responsabilidad individual es esencial para garantizar la efectividad del derecho internacional y para prevenir la recurrencia de estos actos es importante que se complemente y coexista con la responsabilidad de los Estados. Las graves violaciones al derecho internacional y los daños transfronterizos rara vez ocurren sin la participación, negligencia o tolerancia de agentes estatales. Acerca de las atrocidades nazis, Hannah Arendt señaló que "crímenes de este tipo fueron, y únicamente podrían ser, cometidos bajo un derecho criminal y por un Estado criminal". ${ }^{53}$ La responsabilidad estatal es indispensable para la prevención y sanción de estas conductas y no excluyente de los recientes esfuerzos enfocados en la responsabilidad de los individuos o entidades privadas. Los futuros avances en la codificación de la responsabilidad internacional, ya sea en materia de crímenes internacionales o de actividades que causan daños transfronterizos, deberán tomar en cuenta cómo la responsabilidad individual y la responsabilidad internacional de los Estados se complementan con el fin de contribuir a preservar los derechos de los individuos y la armonía entre las naciones.

51 Report of International Joint Commission — United States and Canada: Smelting Co. Casein British Columbia, 25 American Journal of International Law 540 (1931); Corte Internacional de Justicia. Caso del Canal de Corfú (Fondo), I.C.J. Reports 1949 y el Arbitraje concerniente al Lago Lanoux. (1957) 12 R.I.A.A. 281.

52 Lauterpacht, Hersch, International Law and Human Rights, Hamden, Archon Books, reprint 1968, 1950, p. 40.

53 Hannah Arendt, Eichmann in Jerusalem. A Report on the Banality of Evil, Nueva York, The Viking Press, 1963, p. 240. 